\title{
Extraños compañeros de viaje: Cervantes y Mary Shelley
}

\author{
Alfredo Moro*
}

\begin{abstract}
Resumen
Miguel de Cervantes y Mary Shelley parecen, a priori, dos extraños compañeros de viaje. Pese a las evidentes divergencias entre la narrativa de ambos autores, la autora inglesa mostró un notable interés por la vida y obra de Miguel de Cervantes a lo largo de toda su carrera. Este artículo pretende ofrecer un retrato preciso de los intereses cervantinos de la autora de Frankenstein, rastreando con este fin la correspondencia personal de la autora inglesa, su producción narrativa, y finalmente, su contribución al cervantismo: la Life of Cervantes (1837) que Shelley publicaría en la Cabinet Cyclopaedia de Dyonisius Lardner.
\end{abstract}

Palabras Clave: Cervantes; Mary Shelley; recepción del Quijote en Gran Bretaña; siglo XIX.

Title: Strange bedfellows: Cervantes and Mary Wollstonecraft Shelley

\begin{abstract}
Miguel de Cervantes and Mary Shelley do seem, at first sight, two strange bedfellows. Notwithstanding the evident differences between the narrative of both authors, the English novelist showed a notable interest for the life and works of Miguel de Cervantes throughout her literary career. This article intends to offer a precise portrait of the Cervantean interests of the author of Frankenstein, tracing these through her personal correspondence, her narrative production, and finally, through her contribution to the realm of Cervantean studies: Shelley's Life of Cervantes (1837), published in Dyonisius Lardner's Cabinet Cyclopaedia.
\end{abstract}

Key Words: Cervantes; Mary Shelley; reception of Don Quixote in Great Britain; nineteenth century.

* Universidad de Cantabria. alfredo.moro@unican.es / ORCID iD: http://orcid.org/0000-00023652-9753. 


\section{Cómo citar este artículo / Citation}

Moro, Alfredo (2017). «Extraños compañeros de viaje: Cervantes y Mary Shelley», Anales Cervantinos. 49, pp. 325-352, doi: http://dx.doi.org/10.3989/anacervantinos.2017.013.

\section{INTRODUCCIÓN}

Tal y como destaca Erin Webster Garrett (2000: 135), Miguel de Cervantes y la novelista Mary Shelley (1797-1851) quizás resulten, a primera vista, dos extraños compañeros de viaje, especialmente si tenemos en cuenta que la obra del autor español se presenta como un correctivo al tipo de ficción que la autora inglesa escribiría dos siglos más tarde. Sin embargo, pese a las evidentes divergencias entre la narrativa de ambos autores, el interés de Mary Shelley por la obra de Miguel de Cervantes no solamente fue bastante temprano, sino que será constante a lo largo de toda su carrera, abarcando su correspondencia personal, su producción narrativa y cristalizando finalmente en una biografía de Cervantes, su Life of Cervantes, publicada en el tercer volumen de las Lives of the most Eminent Literary and Scientific Men of Italy, Spain, and Portugal (1837), que aparecería en el volumen octogésimo octavo de la Cabinet Cyclopaedia (1830-1841) del irlandés Dionysius Lardner (17931853).

En este artículo me propongo ofrecer un retrato preciso de los intereses cervantinos de la escritora británica, centrándome en tres aspectos fundamentales. En primer lugar, abordaré los testimonios que la propia Mary Shelley ofrece tanto en su primera obra publicada como en su correspondencia personal sobre su interés por Cervantes, para centrarme posteriormente en el análisis de los elementos cervantinos presentes en su producción novelística. Finalmente, dedicaré mi atención a la ya mencionada Life of Cervantes, tratando de reflejar cómo Shelley reproduce una visión de la vida de Miguel de Cervantes en perfecta consonancia con la romantización de la figura del autor español que venía produciéndose en las letras europeas del siglo XIX. A través de esta estructura tripartita se podrá obtener una visión de conjunto sobre la dimensión del influjo de Cervantes en Mary W. Shelley, una influencia que, como se podrá apreciar a continuación, fue cuanto menos, notable.

\section{MARY W. SHELLEY Y SU INTERÉS POR CERVANTES Y ESPAÑA}

El interés de Mary Shelley por Cervantes proviene, con toda seguridad, de su círculo familiar. Su padre, el filósofo William Godwin (1756-1836), ya era un gran admirador del Quijote, novela que consideraba uno de los libros más 
dignos de admiración de toda la literatura universal (Moskal 2000: 19) ${ }^{1}$. El pensador inglés llegó a publicar —asumiendo él mismo el coste de la publicación - una biografía de uno de los primeros traductores del Quijote al inglés, John Philips, en sus Lives of Edward and John Philips (1815), elogiando la novela cervantina como «un monumento incomparable de la literatura y del genio español» (citado en Moskal 2000: 19). Por su parte, Mary Wollstonecraft (1759-1797) hace referencia al Quijote en la obra que le convertiría en un referente del pensamiento feminista, su Vindication of the Rights of Woman (1792). En ella, Wollstonecraft (2002: 28), al mencionar cómo las mujeres se ven abocadas a unas nociones del amor esclavas de la sensualidad y la lujuria, y no de la verdadera amistad, destaca que no pretende «expulsar el amor del mundo por medio del argumento racional», ya que esto «sería ir más allá que Don Quijote, y ofende por igual al sentido común». La figura de Godwin y la lectura de las obras de su madre, Mary Wollstonecraft, parecen haber contribuido en el interés por el Quijote de Mary Shelley, no en vano, ya en la primera obra literaria firmada por Mary Shelley, su History of a Six Weeks Tour through a Part of France, Switzerland, Germany, and Holland, with Letters descriptive of a Sail round the Lake of Geneva, and of the Glaciers of Chamouni (1817), puede encontrarse una mención a la novela de Cervantes, y es que las aventuras del Caballero de la Triste Figura parecen haber acompañado a los Shelley y a Claire Clairmont a lo largo de esta escapada al Continente llevada a cabo en $1816^{2}$. Mary, imbuida por el romance y la aventura que suponía la huida con su amante hacia una Europa devastada por las Guerras Napoleónicas (1792-1815), va a teñir el relato de su viaje con una serie de reminiscencias cervantinas. Como apunta Moskal (2000: 19), el propio viaje se va a ver rodeado por una serie de situaciones claramente evocadoras de las andanzas de don Quijote y Sancho Panza, como por ejemplo

1. Pese a esta fascinación por el Quijote, Godwin no podría evitar convertirse en el blanco satírico de una de las novelas quijotescas de la tradición cervantina inglesa, The Infernal Quixote, de 1801, de Charles Lucas, novela anti-jacobina que emplea la sátira cervantina como medio de ataque político a las ideas de Godwin. En cualquier caso, el interés de Godwin por la literatura española es evidente, tal y como Burton R. Pollin (1964) y Lisa Vargo (2002: xvii) atestiguan. La trama de Caleb Williams (1793) debe mucho, en opinion de Vargo (2002: xvii), al Guzmán de Alfarache de Mateo Alemán, mientras que sus obras St. Leon: a Tale of the Sixteenth Century (1799) y la inacabada Mandeville (1833) cuentan con tramas o localizaciones españolas.

2. El interés de Mary Shelley por la obra de su madre fue constante a lo largo de toda su vida, tal y como muestran sus diarios, en los que la autora inglesa ofrece una información bastante detallada de sus lecturas. En la lista de lecturas de la autora correspondiente a 1814, encontramos referencia a las Letters Written During a Short Residence in Sweden, Norway and Denmark (1796), a la novela Mary, a Fiction (1788) y a The Wrongs of Woman; or Maria (1798). En la lista de 1815 se encuentran las obras póstumas de Wollstonecraft, Posthumous Works of the Author of a Vindication of the Rights of Woman (1798), editada por su propio padre, William Godwin. En una entrada del diario del 6 de diciembre de 1816 ya encontramos una referencia a la lectura de la Vindication of the Rights of Woman (Journals, I: p. 149). Pese a que nunca llegó a conocer a su madre, resulta evidente que Mary tuvo un vasto conocimiento de la obra de Wollstonecraft. 
la compra de una mula que resulta inútil un día después de su adquisición ${ }^{3}$, la contemplación de unos molinos de viento holandeses, que traen a la mente el célebre ataque de don Quijote a los molinos que creía gigantes ${ }^{4}$, o los numerosos altos en el camino derivados del tobillo hinchado de Percy Shelley, que recuerdan a aquellos pasajes en los que el habitualmente malogrado don Quijote se ve incapacitado para proseguir el camino. De hecho, la asociación entre Percy Shelley y el caballero manchego parece haber sido recurrente en el pensamiento de Mary Shelley durante este período, tal y como demuestra una carta al propio Percy Shelley de 1817 en la que se discuten los problemas judiciales del poeta inglés al solicitar la custodia legal de sus hijos: «My sweet Love, you were born to be a Don Quixote and if that celebrated personage had ever existed except in the brain of Cervantes I should certainly form a theory of transmigration to prove that you lived in Spain some hundred years before and fought with windmills» (Letters, I: p. 27) 5 . En otra misiva de 1820, Mary vuelve a asociar a su marido con el Ingenioso Hidalgo, en este caso tras defender a un joven herrero perseguido por un hombre con un paraguas, episodio que trae a su memoria la intervención de don Quijote a favor de Andrés en la primera parte de la novela (I: cap. 4$)^{6}$. En cualquier caso, las reminiscencias cervantinas parecen haber sido habituales en la intimidad de los Shelley, no en vano, en una fecha mucho más tardía como agosto de 1832 , encontramos una carta de Mary Shelley a su amiga Maria Gisborn, en la que relata cómo su único hijo, Percy Florence Shelley, intenta convencerla para que le deje comer en soledad, aludiendo a la costumbre de Sancho Panza de disfrutar de alguna que otra cebolla a escondidas (Selected Letters: p. 247) ${ }^{7}$. Como destaca Garrett (2000: 138), este incidente sugiere que Don Quijote fue un texto al que Shelley y su hijo podían referirse con una cierta familiaridad,

3. «Finding our ass useless, we sold it before we proceeded on our journey, and bought a mule, for ten Napoleons. About nine o'clock we departed. We were clad in black silk. I rode on the mule, which carried also our portmanteau; $\mathrm{S}$ and $\mathrm{C}$ followed, bringing a small basket of provisions. At about one we arrived at Gros Bois, where, under the shade of trees, we ate our bread, thinking of Don Quixote and Sancho» (History of a Six Weeks Tour: p. 8).

4. «The roads were excellent, but the Dutch have contrived as many inconveniences as possible. In our journey of the day before, we had passed by a windmill, which was so situated with regard to the road, that it was only by keeping to the opposite side, and passing quickly, that we could avoid the sweep of the sails» (History of a Six Weeks Tour: p. 23).

5. [Mi dulce amor, naciste para ser un don Quijote, y si ese celebrado personaje alguna vez existió excepto en la mente de Cervantes, seguramente debería formar una teoría de la transmigración para probar que viviste en España unos cientos de años atrás y que luchaste contra molinos de viento].

6. «Don Quixote did not like to leave the boy in thrall, but deafened by the tall strider's vociferations and overcome by Clare's importunities he departed» [Don Quijote no quiso dejar al chico en la estacada, pero ensordecido por las voces del caminante y de las importunidades de Clare, acabó marchándose] (Letters: p. 132).

7. «On going away he insisted on having his supper alone in his room-telling me, to persuade me, that Sancho liked an onion behind a door, and why might he not enjoy the pleasures of solitary fare?» [Al marcharnos, insistió en cenar solo en su habitación, diciéndome, para persuadirme, que a Sancho le gustaba disfrutar de una cebolla a escondidas, y ¿por qué no podría él mismo disfrutar de los placeres de la soledad?]. 
por lo que podemos intuir un conocimiento profundo de la novela cervantina por parte de la escritora inglesa, y también por parte del joven Percy Florence, al que las aventuras del Ingenioso Hidalgo y de Sancho Panza resultaron un recurso útil para eludir las atenciones de una madre sobreprotectora ${ }^{8}$.

Al mismo tiempo, también cabría resaltar que otros personajes cercanos al círculo de los Shelley compartieron este interés por Cervantes. El propio médico de los Shelley, el italiano Andrea Vaccá Berlinghieri (1772-1826) - que aparentemente habría participado en la toma de la Bastilla- fue un gran admirador del autor español (Moskal 2000: 27), al que probablemente asoció con las ideas defendidas por Percy y Mary9 ${ }^{9}$ Precisamente esta ideología progresista tuvo como resultado un gran interés por parte de Mary respecto a los acontecimientos históricos acaecidos en España como consecuencia de la invasión napoleónica de 1808. Tal y como ha estudiado Jeanne Moskal (2000: 22-28), la lucha del pueblo español por su soberanía despertó en el Reino Unido una ola de simpatía por España, tradicionalmente asociada a la Leyenda Negra. Los levantamientos del 3 de mayo en Madrid transformaron

8. En la correspondencia de Shelley pueden encontrarse otras referencias ocasionales a la obra cervantina. En una misiva a John Howard Payne de 1825, Shelley se autodenominará, muy significativamente, como "Quijote femenino" (Letters, I: p. 499-500), mientras que un año más tarde, el 4 de abril de 1826, la autora inglesa se dirige a su erudito colega Sir John Bowring, que dos años antes había publicado una colección de vieja poesía castellana, Ancient Poetry and Romances of Spain, para pedirle prestados algunos libros españoles con los que aumentar su biblioteca, en la que Cervantes y Calderón ocupaban un lugar significativo, y entre los que sorprendentemente se incluye el Gil Blas de Lesage: «I want you to recommend to me and even to lend me some Spanish books — my stock consists of Calderon [sic] — Don Quixote — Gil Blas and a few other plays — I like old romances — if you have the Conquista de Granada, I should like it — I hope to see you soon» [Me gustaría que me recomendases y que incluso me prestases algunos libros españoles — mi género consiste en Calderón, Don Quijote, Gil Blas y algunas otras obras teatrales. También me gustan las novelas antiguas, si tienes la Conquista de Granada, me gustaría. Espero verte pronto] (Letters, I: p. 512).

Finalmente, la última referencia al Quijote que podemos encontrar en la correspondencia de Shelley data de marzo de 1831, en la que en una epístola a Edward John Trelawny, amigo de los Shelley y Byron desde su encuentro en Italia en 1822, Mary informa a su correspondiente del matrimonio de Elizabeth St. Aubin, acontecimiento que le dejará "sin una Dulcinea" (Letters, II: p. 133).

9. Junto a Vaccà, hay que destacar que algunos de los integrantes del círculo romántico en el que se movían los Shelley mostraron un notable interés por la obra de Cervantes. Lord Byron, en su Don Juan (1821) declara a Cervantes como el responsable de la decadencia española en los célebres versos del decimotercer canto de su poema:

$$
\begin{gathered}
\text { Cervantes smiled Spain's Chivalry away; } \\
\text { A single laugh demolished the right arm } \\
\text { Of his own country; - seldom since that day } \\
\text { Has Spain had heroes. While Romance could charm, } \\
\text { The world gave ground before her bright array; } \\
\text { And therefore have his volumes done such harm, } \\
\text { That all their glory, as a composition, } \\
\text { Was purchased by his land's perdition (Works: p. 768). }
\end{gathered}
$$

Por su parte, Leigh Hunt, a quien Mary Shelley asociará con Cervantes en una de sus cartas (Letters, II: p. 292-293), había mostrado un gran interés por Cervantes, tal y como muestra el recuerdo del autor español en su viaje entre Argel y Málaga (Autobiography, II: p. 288) y su inclusión en su particular parnaso literario en The Feast of the Violets (Poetical Works: p. 125) junto con Chaucer y Shakespeare. 
a España en un símbolo de la libertad, tanto para jacobinos como para conservadores, y la literatura española se convertirá en una auténtica moda durante este primer tercio del siglo XIX, tal y como atestigua la traducción al inglés del Cantar del Mio Cid [Chronicle of the Cid], llevada a cabo por el poeta romántico Robert Southey en 1808, que también había traducido el Amadis de Gaula [Amadis of Gaul] en 1803; o el primer canto del Childe Harold's Pilgrimage (1812) de Lord Byron, en el que se puede encontrar la figura de Agustina de Aragón, The Maid of Saragossa ${ }^{10}$. En 1815, William Hazlitt llegará incluso a asociar a Cervantes con el ideario jacobino, considerándole «el conservador de la libertad española» (citado en Moskal 2000: $25)^{11}$. Mary Shelley también participó de este interés general por España, siguiendo de manera atenta la proclamación en Cádiz de la Constitución de 1812 y la ratificación de la Constitución por parte de Fernando VII en 1820, con la consiguiente abolición de la Inquisición, acontecimiento que le lleva a poner por escrito su deseo de estar en Madrid en esos momentos (Letters, I: p. 141 $)^{12}$. Si bien Mary no llegó nunca a visitar España, su interés por la patria de Cervantes permanecerá latente a lo largo de toda su vida, llegando incluso a aprender el castellano para poder disfrutar de la literatura española en el original, y más específicamente del Quijote cervantino ${ }^{13}$.

10. Shelley fue una asidua lectora de la obra "española" de Southey. En sus listas de lecturas de los años que van de 1815 a 1817 aparecen las Letters from England (1807), el poema de temática visigótica Roderick, the last of the Goths (1814) y la traducción de Southey del Amadis, su Amadis of Gaul (1803) (Journals, II: 677). Como Destaca Vargo (2002: xvi), Southey ofreció ayuda a Shelley en la preparación de su biografía de Camoëns.

11. El interés británico por la cultura española no será menor durante las décadas posteriores. El yerno de Sir Walter Scott, John Gibson Lockhart, editará junto a John Bowring varios volúmenes con traducciones de poesía española, mientras que Felicia Hemans escribirá su England and Spain, or Valour and Patriotism (1818), así como traducciones de otros poetas del ámbito hispánico y lusófono. El norteamericano Washingon Irving, amigo de Mary Shelley, dedicará varias de sus obras a España y su historia, entre ellas su Colombus (1828), Conquest of Granada (1829) y la célebre Legends of the Alhambra (1832) (Vargo 2002: xvii).

12. «The Beloved Ferdinand has proclaimed the Constitution of 1812 and called the Cortes - the Inquisition is abolished - The dungeons opened and the Patriots pouring out - This is good, I should like to be in Madrid now» [Fernando el Deseado ha proclamado la Constitución de 1812, y llamado a las Cortes - la Inquisición ha sido abolida - las mazmorras han sido abiertas, y los patriotas escapan de ellas - Todo esto es bueno, me gustaría estar en Madrid en estos momentos]. Cabe destacar que, como ha demostrado Moskal (2000: 27), Mary Shelley pudo contar con información de primera mano sobre el desarrollo de los acontecimientos en España, ya que su hermanastro, Charles Clairmont, trabajó como tutor en Valencia en enero de 1819, publicando para el Morning Chronicle un reportaje sobre la ejecución de los conspiradores que planeaban ejecutar a Francisco Elío, Capitán General de Valencia.

13. Este interés por la literatura española no se manifiesta únicamente en los intereses cervantinos de Mary Shelley, sino que puede ampliarse a un buen número de autores auriseculares, que Shelley incluye en sus Spanish Lives. Particular atención le mereció la obra de Pedro Calderón de la Barca, dramaturgo por el que su marido, Percy B. Shelley, sintió una auténtica devoción. Sobre los intereses calderonianos de Shelley, puede consultarse Moro (2015b).

A su vez, cabe resaltar que los diarios de Shelley son bastante precisos en lo que se refiere a las fechas en las que tanto ella como su marido comienzan a leer el Quijote y a aprender la lengua castellana. El diario de Shelley data el comienzo de la lectura conjunta del Quijote en octubre de 1816, concretamente el sábado 6 (Journals, I: p. 139), concluyendo el 7 de noviembre de 1816 (Journals, 


\section{EL QUIJOTE Y LA PRODUCCIÓN NOVELÍSTICA DE MARY SHELLEY}

Cabe preguntarse, por lo tanto, hasta qué punto este interés por España y por Cervantes llegó a materializarse en la producción novelística de la autora inglesa. El escaso interés que la relación entre Cervantes y Shelley ha despertado en la crítica cervantina - a excepción de las contribuciones de Moskal (2000), Garrett (2000), Donahue (2009), Moro (2013 y 2015a) y Sánchez Jiménez (2016) - invitaría a pensar que la atención que Mary Shelley dedicó a Cervantes no tuvo consecuencias literarias ${ }^{14}$. Sin embargo, existen claras afinidades estructurales y temáticas entre la obra de Cervantes y la de Mary Shelley, desde su primera novela y obra maestra, Frankenstein, or the Modern Prometheus (1818), hasta sus dos últimas novelas, las hoy prácticamente olvidadas Lodore (1835) y Falkner (1837).

\subsection{Frankenstein, or the Modern Prometheus (1818)}

En la introducción a la edición de Frankenstein de 1831 puede encontrarse una clara referencia al Quijote. En esta, Shelley se sirve de una de las numerosas sentencias de Sancho Panza (II: p. 23) para relatar las circunstancias que rodearon a la gestación de la novela en la célebre noche tormentosa de la Villa Diodati, declarando que «Everything must have a beginning, to speak in Sanchean Phrase» (Frankenstein: p. 8) ${ }^{15}$. Esta referencia, que podría resultar anecdótica a primera vista, cobra más importancia al leer la novela de la escritora inglesa desde un prisma cervantino. En primer lugar, existen toda una serie de paralelos estructurales entre ambas novelas, fundamentalmente en lo que se refiere a su engranaje narratorial, tal y como han apuntado Garrett (2000: 140-141) y Donahue (2009: 183). Tanto el Quijote como Frankenstein se apoyan en un tejido narrativo compuesto por una serie de narradores que aumentan la distancia entre el lector y el autor del discurso, relativizando y cuestionando la veracidad del relato, algo que aleja al lector de una visión monológica y única de los acontecimientos (Donahue 2009: 183). En Frankenstein, la narración descansa sobre tres relatos distintos de

I: p. 145). En 1819 Shelley anota una lectura del Persiles en mayo de 1819 (Journals, I: p. 265), año en el que comienza su contacto con la obra de Calderón de la Barca, que le llevará a comenzar a aprender castellano un año más tarde, en el mes de noviembre (Letters, I: p. 340). Durante este mes mezcla la lectura de Calderón con la segunda lectura de Don Quijote, parece que esta vez en el original.

14. Laurence Porter (2005), como Garrett, también hace referencia al paralelo entre Safie y Zoraida, si bien no cita el artículo de la profesora norteamericana. Frederick de Armas (2011) sí que se hace eco de las ideas de Garrett en torno a los paralelos entre Safie y Zoraida. Respecto a los intereses cervantinos del círculo de los Shelley puede consultarse la obra de Jean de Palacio (1969). Cabe resaltar que ninguno de estos estudios abordan directamente la problemática que nos ocupa.

15. [Todo ha de tener un comienzo, por hablar a la manera de Sancho]. 
los hechos que constituyen la novela. El lector nunca experimenta una versión directa de estos por parte de los principales actores del relato, sino que la figura de un mediador textual se impone siempre entre la narración a disposición del lector y la versión que los protagonistas ofrecen de los hechos (Donahue 2009: 183). De esta manera, el explorador polar Robert Walton relata la historia del doctor Victor Frankenstein, que dice haber transcrito lo más literalmente posible a través de las palabras de este:

I have resolved every night, when I am not imperatively occupied by my duties, to record as nearly as possible in his own words, what he related during the day. If I should be engaged, I will at least make notes. This manuscript will doubtless afford you the greatest pleasure, but to me, who know him, and who hear it from his own lips, with what interest and sympathy shall I read it in some future day! Even now, as I commence my task, his full-toned voice swells in my ears; his lustrous eyes dwell on me with all their melancholy sweetness; I see his thin hand raised in animation, while the lineaments of his face are irradiated by the soul within. Strange and harrowing must be his story; frightful the storm which embraced the gallant vessel on its course, and wrecked it-thus! (Frankenstein: p. 30) ${ }^{16}$.

Por su parte, el propio doctor narra - de nuevo, aparentemente de memoria - a Robert Walton el relato que la Criatura le ofrece de su existencia desde su creación hasta su encuentro con ella, relato que aporta un interesante contraste dialógico respecto a la versión que el doctor ofrece de ese mismo período:

For the first time also, I felt what the duties of a creator towards his creature were, and that I ought to render him happy before I complained of his wickedness. These motives urged me to comply with his demand. We crossed the ice, therefore, and ascended the opposite rock. The air was cold, and the rain again begun to descend: we entered the hut, the fiend with an air of exultation, I with a heavy heart, and depressed spirits. But I con-

16. [He decidido que cada noche, cuando no esté imperativamente obligado por mis quehaceres, documentaré de la manera más cercana a sus propias palabras lo que ha narrado durante el día. Si estoy ocupado, al menos intentaré tomar unos apuntes. Este manuscrito te otorgará sin duda alguna el mayor de los placeres, pero para mí, que le conozco y que he escuchado su narración de sus propios labios, ¡con qué interés y simpatía lo leeré en algún día venidero! Incluso ahora, mientras comienzo mi tarea, su voz de tonalidad fuerte retumba en mis oídos; sus brillantes ojos permanecen en mí con su melancólica dulzura; veo su delgada mano elevada animadamente, mientras que las arrugas de su rostro se encienden por el alma que mora dentro de él. Extraña y desgarradora debe de ser su historia, espantosa la tormenta que abrazó a la galante nave en su camino, y que la hizo naufragar...de esta manera]. En este artículo he empleado la edición de Frankenstein de 1831, concretamente la tercera edición de la novela, al ser la última versión revisada por la autora. En cualquier caso, me referiré de manera ocasional a algunos pasajes de la primera edición, la de 1818, que desaparecen en la versión de 1831, pero que nos revelan algunos aspectos interesantes en torno al interés de Shelley por la literatura española. Todas las traducciones de este artículo son mías, exceptuando las de la Life of Cervantes, caso en el que he empleado la magnífica traducción de Antonio Sánchez Jiménez. A su vez, todas las cursivas de las citas responden a mi énfasis. 
sented to listen, and seating myself by the fire which my odious companion had lighted, he thus began his tale (Frankenstein: p. 102) ${ }^{17}$.

De este modo, se establece una distancia de dos agentes narrativos - Walton y el doctor Frankenstein - entre la narración de la Criatura y el lector, creándose un juego de cajas chinas que explicita la naturaleza mediada, y no definitiva de la narración. Esta estructura narrativa recuerda a la compleja red de narradores que Cervantes crea en el Quijote y el juego de distancia y control narratorial que se establece en la novela, y que ha sido magistralmente analizado por Ruth El Saffar (1975). No parece por lo tanto excesivamente descabellado pensar en una influencia decisiva de Cervantes en la concepción estructural de la novela de Shelley, hipótesis que cobra más sentido si tenemos en cuenta que, tal y como ha señalado Garrett (2000: 138), Percy y Mary Shelley leyeron de manera conjunta el Quijote del 6 de octubre al 7 de noviembre de 1816, precisamente un período crítico en la gestación de Frankenstein.

En cualquier caso, los paralelos estructurales entre la obra de Cervantes y Frankenstein no acaban en la similar disposición narrativa de ambas novelas. Tal y como señalan Garrett (2000: 139) y Donahue (2009: 184), el Quijote y Frankenstein muestran una similar inclusividad genérica, manifestada fundamentalmente en el recurso de la interpolación, que tan importante papel juega en el Quijote y en la novela de Shelley. Precisamente, una de las historias interpoladas de Frankenstein, la historia de Safie, la otomana huida y adoptada por la familia de los De Lacey (Frankenstein 122-127) muestra una extraordinaria semejanza con la historia de Zoraida, la amada del cautivo cristiano en la narración interpolada del Quijote (399-499). Los paralelos entre ambas interpolaciones han sido analizados de manera excepcional por Garrett (2000: 140-153), que ha señalado a su vez el similar uso que Cervantes y Shelley respectivamente hacen de la venta de Juan Palomeque y de la cabaña de los De Lacey, ya que ambos lugares se erigen como un lugar de encuentro en el que se desvelan los misterios que envuelven las peripecias vitales de los distintos protagonistas de las historias interpoladas (Garrett 2000: 148). Parece, por lo tanto, que Shelley, en su lectura del Quijote, asimiló perfectamente la compleja estructura narrativa de la novela cervantina.

En lo que se refiere a los paralelos temáticos entre el Quijote y la primera novela de Shelley, cabría destacar la naturaleza marcadamente quijotesca de dos de los principales narradores de la novela, el explorador polar Robert Walton y el propio Victor Frankenstein. En cuanto al explorador inglés, el lector pronto aprecia cómo su fascinación por descifrar los misterios del

17. [Por vez primera sentí cuáles eran los deberes de un creador respecto a su criatura, y el hecho de que debería hacerle feliz antes de quejarme de su malevolencia. Estos motivos me apresuraron a admitir su petición. El aire era frío, y la lluvia comenzó de nuevo a descender: entramos a la cabaña, mi enemigo con un aire exultante, y yo con un corazón apenado y el espíritu deprimido. Pero consentí en escucharle, y sentándome cerca del fuego que mi odiado compañero había encendido, empezó de esta manera su relato]. 
océano y su amor por lo maravilloso se ven motivados por unas fuentes reconociblemente literarias, en concreto por la producción poética del poeta lakista Samuel Taylor Coleridge (1772-1834):

I have often attributed my attachment to, my passionate enthusiasm for, the dangerous mysteries of the ocean, to that production of the most imaginative of modern poets. There is something at work in my soul, which I do not understand, I am practically industrious — pains taking - a workman to execute with perseverance and labour - but besides this, there is a love for the marvelous, a belief in the marvelous, intertwined in all my projects, which hurries me out of the common pathways of men, even to the wild and unvisited regions I am about to explore (Frankenstein: p. 21) ${ }^{18}$.

La causa del entusiasmo por lo maravilloso y por lo inusual de Robert Walton no es otra que un modelo literario concreto. De hecho, si analizamos estas primeras cartas en las que Walton narra a su hermana los orígenes de su proyecto de exploración polar, nos encontraremos con una educación libre, basada en las crónicas de viajes que pudo encontrar en la biblioteca de su tío (pp. 16-17 y 19), reproduciendo de esta manera el patrón dieciochesco de Quijotes jóvenes en los que la falta de una figura paterna y una educación "desregulada" acarrean un quijotismo juvenil que ha de ser curado por la experiencia ${ }^{19}$, algo que el propio explorador polar explicita al expresar la necesidad de encontrar un amigo para «regular mi mente» (p. 19) ${ }^{20}$. Si bien

18. [Habitualmente he atribuido mi apego y mi entusiasmo apasionado por los misterios del océano a aquella producción del más imaginativo de los poetas modernos. Hay algo dentro de mi alma que no entiendo. Soy un trabajador particularmente laborioso y asiduo a la hora de llevar a cabo mi empresa con perseverancia y tesón, pero además de esto, hay un amor por lo maravilloso, una creencia en lo maravilloso, mezclada en todos mis proyectos, que me aparta de los senderos habitualmente pisados por los hombres, incluso hasta las regiones salvajes e inexploradas que estoy a punto de explorar].

19. Waverley, or 'Tis Sixty Years Since (1814), de Sir Walter Scott constituye el ejemplo más logrado de esta tendencia. En la novela de Scott, el joven Waverley, marcado por una educación desregulada por la muerte de su madre y las repetidas ausencias paternas, sustituye la educación reglada por una educación libresca, basada en la lectura de una literatura de claro corte romancesco, lecturas que tienen como consecuencia que el protagonista de Scott «navegue por el mar de los libros, como una nave, sin piloto ni timonel» (Waverley 13). Significativamente, ante la ausencia paterna, es el tío de Waverley, Sir Everard Waverley, quien se encarga, junto con un viejo preceptor, de la educación (fallida) del joven noble inglés. Cabe destacar que la temática de la desregulación educativa y consecuente lectura desmesurada por parte de un joven protagonista, encuentra un claro precedente en el Female Quixote (1752) de Charlotte Lennox, cuya protagonista, Arabella, desarrolla un gusto por la lectura de obras de corte romancesco que puede encontrar en la biblioteca paterna. Significativamente, al igual que en Waverley, Arabella carece de madre. El modelo para este tipo de novelas cuyos protagonistas son jóvenes lectores se encuentra claramente en la narrativa alemana de la segunda mitad del siglo XVIII, más concretamente en la obra de autores como Neugebauer o Wieland, tal y como ha sugerido Moro (2016: 219-231).

20. Ya en su primera carta, Walton ofrece un retrato bastante preciso de su educación libresca: «This expedition has been the favourite dream of my early years. I have read with ardour the accounts of the various voyages which have been made in the prospect of arriving at the North Pacific Ocean through the seas which surround the pole. You may remember, that a history of all the voyages made for purposes of discovery composed the whole of our good uncle Thomas's library. My education was 
Walton no transforma imaginativamente la realidad que le rodea de acuerdo a sus modelos romancescos, tal y como lo hiciera don Quijote, su punto de partida es tremendamente similar al del hidalgo manchego, ya que es la literatura la que motiva una búsqueda que separa a Walton del resto de la humanidad en su intento por alcanzar unas regiones desconocidas, cuya existencia en la novela es únicamente atestiguada por la literatura.

En cuanto al doctor Frankenstein, que en muchos sentidos puede ser visto como un doble simbólico del propio Walton, los paralelos con la figura quijotesca no resultan menos interesantes. Al contrario que Walton, Frankenstein no llega a fundamentar su deseo fáustico de conocer todas las cosas indiscriminadamente (Frankenstein: p. 37) en unos modelos literarios concretos, pero su interés por las leyes más secretas de la naturaleza se ve marcado por unos modelos científicos que en el momento histórico en el que se desarrolla la novela - finales del siglo XVIII o principios del siglo XIX - resultan tan desfasados como la caballería andante en la España del siglo XVII, dotando al doctor suizo de una cierta coloración quijotesca, algo que Darcy Donahue (2009: 183) ha reconocido muy acertadamente ${ }^{21}$. Muy al comienzo de su

neglected, yet I was passionately fond of reading. These volumes were my study day and night, and my familiarity with them increased that regret which I had felt, as a child, on learning that my father's injunctions had forbidden my uncle to allow me to embark in a seafaring life» (pp. 16-17) [Esta expedición ha sido el sueño favorito de mis años tempranos. He leído con ardor las crónicas de los varios viajes que se han realizado con la intención de llegar al Océano Pacífico Norte a través de los mares que rodean el polo. Quizás recuerdes, que una historia de todos los viajes realizados con objetivos de descubrimiento componía la totalidad de la biblioteca de nuestro buen tío Thomas. Mi educación fue desatendida, y aún así sentía una apasionada afición por la lectura. Estos volúmenes fueron mi estudio durante noche y día, y mi familiaridad con ellos incrementó el arrepentimiento que sentí cuando era niño al conocer las instrucciones de mi padre por las que prohibía a mi tío embarcarme en la vida marinera].

En este sentido, cabe destacar que Waverley se encontraba entre las lecturas de Mary Shelley del 23 de marzo, en la entrada de su diario inmediatamente anterior a las correcciones de Frankenstein (Journals, I: 166), por lo que la hipótesis de que la figura de Walton en la versión de 1818 estuviera moldeada, al menos en lo que se refiere a su educación deficitaria, en la del Edward Waverley, no parece del todo descabellada.

21. Además, cabe destacar que el quijotismo del doctor Frankenstein evoca el recuerdo de otra novela perteneciente a la tradición cervantina inglesa del siglo XVIII, concretamente The Philosophical Quixote, or the Memoirs of David Wilkins, de 1782, que viene a satirizar los intentos de aplicar los descubrimientos filosóficos de este último tercio del siglo XVIII al campo de la medicina. Wilkins «reads everything that appears on philosophical and medical subjects, and makes it a rule to repeat the experiments [...]. His prejudice in favour of novelty seemed to be so great that perhaps there was no doctrine, however absurd, which he would not readily swallow» (The Philosophical Quixote: pp. 44-45) [Lee todo lo que aparece en torno a temas filosóficos y médicos, y se marca, como regla, repetir todos los experimentos [...]. Su prejuicio en favor de la novedad parecía ser tan grande que quizás no había doctrina, por absurda que esta fuera, que no estuviera dispuesto a tragarse].

Esta falta de discriminación respecto a las teorías científicas vincula el quijotismo de Frankenstein con el de Wilkins, si bien la intención satírica es mucho más directa y evidente en esta novela anónima, y el objeto de la sátira en la novela de Shelley no es la ciencia contemporánea, como en el caso del Philosophical Quixote, sino las anacrónicas teorías pseudo-científicas que el joven Frankenstein trata de aplicar y que la perspectiva ilustrada, que precisamente se critica en el Philosophical Quixote, trata de censurar. En este sentido, se debe destacar que el Philosophical Quixote no se encuentra entre las lecturas de los Shelley ni en los diarios y correspondencia de la autora. 
narración, en el segundo capítulo de la novela, Frankenstein relata la influencia decisiva de la lectura de Cornelius Agrippa (1486-1535) durante su adolescencia, algo que despierta su entusiasmo desmedido por escrutar las profundidades de la naturaleza:

Natural philosophy is the genius that has regulated my fate; I desire, therefore, in this narration, to state those facts which led to my predilection for that science. When I was thirteen years of age, we all went on a party of pleasure to the baths near Thonon; the inclemency of the weather obliged us to remain a day confined to the inn. In this house, I chanced to find a volume of the works of Cornelius Agrippa. I opened it with apathy, the theory which he attempts to demonstrate, the wonderful facts which he relates, soon changed this feeling into enthusiasm. A new light seemed to dawn upon my mind; and bounding with joy, I communicated my discovery to my father. My father looked at the titlepage of my book, and said 'Ah! Cornelius Agrippa! My dear Victor, do not waste your time upon this; it is sad trash! (Frankenstein: pp. 38-39) ${ }^{22}$.

Las advertencias de la figura paterna no sirven sino para reavivar el interés por la Filosofía Natural, cuyos poderes son definidos por el ya maduro Frankenstein que nos narra su historia como "quiméricos" o como "sistemas caducos" (pp. 39-40). De Agrippa se produce una transición a las "locas extravagancias" de Alberto Magno (1193/1206-1280) y de Paracelso (14931541), algo que lleva al joven doctor a empresas ciertamente quijotescas como la búsqueda de la piedra filosofal, el elixir de la vida eterna o la adquisición del poder de convocar a fantasmas y demonios (pp. 39-40) ${ }^{23}$. Como es de esperar, todas estas empresas acaban fracasando, algo que el joven ginebrino imputa en ese momento a su propia inexperiencia y errores, en lugar de reconocer la evidente imposibilidad de sus quiméricas aspiraciones.

A su vez, cabe destacar cómo Frankenstein no está solo en sus tendencias quijotescas. Su mejor amigo de la infancia, Henry Clerval, muestra un claro carácter quijotesco gracias a su fascinación por las novelas de caballerías:

22. [La filosofía natural es el genio que ha marcado mi destino; deseo, por lo tanto, exponer en esta narración aquellos acontecimientos que desembocaron en mi predilección por esta ciencia. Cuando contaba con la edad de trece años, todos realizamos una excursión de recreo en los baños cerca de Thonon; las inclemencias del tiempo nos obligaron a permanecer un día encerrados en una venta. En este local encontré por casualidad un volumen con las obras de Cornelius Agrippa. Lo abrí con apatía; la teoría que trata de demostrar, y los hechos maravillosos que narra, pronto cambiaron este sentimiento por uno de entusiasmo. Una nueva luz pareció amanecer sobre mi mente; y saltando de alegría, comuniqué mi descubrimiento a mi padre. Mi padre lanzó una mirada al título del libro, y dijo: "Ah, Cornelius Agrippa. Mi querido Victor, no gastes tu tiempo en esto, es una triste bazofia"].

23. De hecho, el carácter anacrónico de estos modelos científicos es resaltado en la primera edición de la novela de 1818. Una vez que el joven Victor comienza sus estudios en la universidad alemana de Ingolstadt, relata al Dr. Krempe el contenido de sus lecturas juveniles. Este, no sin cierta ironía, señala cómo «no esperaba, en este siglo ilustrado, encontrar un discípulo de Alberto Magno y Paracelso», enfatizando cómo «cada minuto malgastado en esos libros está profunda y enteramente perdido» (Frankenstein 1818: p. 29). 
Henry Clerval was the son of a merchant of Geneva. He was a boy of singular talent and fancy. He loved enterprise, hardship, and even danger, for its own sake. He was deeply read in books of chivalry and romance. He composed heroic songs, and began to write many a tale of enchantment and knightly adventure. He tried to make us act plays, and to enter into masquerades, in which the heroes of Roncesvalles, of the Round Table of King Arthur, and the chivalrous train who shed their blood to redeem the holy sepulcre from the infidel (Frankenstein: p. 37) ${ }^{24}$.

Los pasatiempos juveniles de Clerval, compartidos por Frankenstein, revelan una naturaleza quijotesca que resulta difícil ignorar, y que define los juegos de infancia del protagonista de la novela de Shelley, revelando una influencia cervantina que desgraciadamente ha pasado bastante desapercibida.

Mediante su asociación del quijotismo a la categoría del entusiasmo - claramente divergente respecto a nociones anteriores del término, más vinculadas al fanatismo religioso de los Puritanos -25 Shelley intencionalmente vincula lo quijotesco con lo prometeico o fáustico, algo que converge, como destaca Garrett (2000), en las dudas que la obra expresa respecto a la idealización romántica del individuo y su voluntad de poder ${ }^{26}$. El descalabro de las empresas románticas de Victor Frankenstein y Robert Walton, no muy diferente al que don Quijote experimenta en su búsqueda caballeresca, resalta el inevitable fracaso del proyecto romántico de transcendencia. Quizás el poeta romántico no pueda, o no deba, ser el legislador no reconocido del mundo, tal y como Percy B. Shelley abanderó en su Defence of Poetry ${ }^{27}$. En cualquier

24. [Henry Clerval era el hijo de un mercader de Ginebra. Era un chico de un talento e imaginación singulares. Amaba la iniciativa, la adversidad e incluso el peligro por sí mismos. Profundamente leído en los libros de caballería, componía cantos heroicos, y comenzó a escribir más de un cuento de encantamiento y aventura caballeresca. Intentó que representásemos obras teatrales, y que lleváramos a cabo mascaradas, en las que los personajes eran tomados de los héroes de Roncesvalles, de los caballeros de la Mesa del Rey Arturo, y del séquito caballeresco que derramó su sangre por redimir el Santo Sepulcro de las manos de los infieles]. En este sentido, cabe destacar que la edición de 1818 ofrece unos modelos de lectura distintos, concretamente añade el Orlando Furioso de Ludovico Ariosto - lectura, por otra parte, compartida con el joven Waverley de Scott-, San Jorge, y de manera muy significativa, Amadís de Gaula (Frankenstein 1818: p. 21). En la edición de 1818 la primera descripción de Clerval se inserta en el relato que el Dr. Frankenstein hace de su juventud, en el primer capítulo de la novela, mientras que en la edición de 1831, este aparece posteriormente, en el capítulo segundo.

25. Respecto a la asociación entre quijotismo y entusiasmo religioso durante los siglos XVII y XVIII, bien presente en la obra de Samuel Butler, Hudibras y en el Spiritual Quixote de Robert Graves, puede consultarse la obra de Paulson (1998: 8-12). Shelley vuelve a mostrar que su asociación entre quijotismo y entusiasmo tiene un carácter claramente diferenciado respecto al de Butler o Graves en su Life of Cervantes, en la que declara que el carácter sublime del Quijote «warms the heart of the enthusiast» (Lives 119), o lo que es lo mismo «anima el corazón del entusiasta» (Vida de Cervantes: p. 41).

26. «A close Reading of the texts indicates that Mary Shelley not only consciously appropriated, but also intentionally collapsed elements of Cervantes' text which she judged most able to illustrate her misgivings regarding Romantic idealization of the individual and his or her will to power» (Garrett 2000: 235).

27. «Poets, according to the circumstances of the age and nation in which they appeared, were called in early epochs of the world legislators and prophets: a poet essentially comprises and uses 
caso, el uso por parte de Mary Shelley de la idea del entusiasmo desmedido y su buscada asociación con lo quijotesco revela cómo la novela de Cervantes puede ofrecer una nueva luz sobre la reescritura del mito de Prometeo llevada a cabo por la escritora inglesa, revelando cómo la influencia de Cervantes en la primera y más famosa novela de Mary Shelley va mucho más allá de la referencia a la sabiduría sanchesca presente en el famoso prólogo de la edición de 1831 .

\subsection{The Last Man (1824)}

Si en Frankenstein Shelley fue capaz de emplear con gran maestría el juego de distancia y control narratorial propio del Quijote, en The Last Man (1824), una novela de temática apocalíptica y de ciencia ficción que relata el fin de la especie humana, la autora inglesa va a hacer uso del juego cervantino de la ficción de fuentes y del manuscrito encontrado. La introducción a la novela sitúa al lector en la bahía de Nápoles en el año 1818, donde la narradora inicial y su acompañante, claros trasuntos literarios de Mary y Percy Shelley, se disponen a visitar la gruta en la que la tradición local ubica la supuesta cueva de la Sibila cumana. Tras atravesar unos laberínticos pasajes de la cueva, la narradora y su acompañante alcanzan una estancia, tenuemente iluminada, en la que encuentran una serie de hojas y fragmentos de cortezas, que forman unos extraños manuscritos en idiomas modernos y antiguos. Estos papeles resultan ser las predicciones de la Sibila cumana, en la que se encuentra la narración del fin de la especie humana por el último hombre sobre la tierra, Lionel Verney, narración que constituye el grueso de la novela que el lector tiene entre sus manos (The Last Man: p. 5-6). La narradora asume la función de editora y traductora de las predicciones de la Sibila, revelándose como un claro intermediario textual entre el supuesto texto original y el lector; efectuando un proceso de selección y traslación al inglés de las profecías. Las similitudes con el papel jugado por las figuras del editor y el traductor de la novela cervantina son evidentes, especialmente si tenemos en cuenta el ambiguo vaivén entre supuesta fidelidad al original - la narradora se refiere a su traducción como el «recital que he transcrito fielmente de mis materiales» (p. 7) - y la creatividad que la editora-traductora confiesa, ya que llega incluso a admitir cómo las profecías:

... obscure and chaotic as they were, [...] owe their present form to me, their decipherer, as if we should give to another artist, the painted fragments which form the mosaic copy of Raphael's Transfiguration in St. Peter's; he

both characters» [Los poetas, de acuerdo con las circunstancias de la era y nación en la que aparecen, fueron llamados en épocas tempranas del mundo legisladores y profetas: un poeta esencialmente abarca y usa ambos papeles] (The Major Works 677). 
would put them together in a form, whose mode would be fashioned by his own peculiar mind and talent (The Last Man: 6) ${ }^{28}$.

La narradora reconoce, por lo tanto la «distortion and diminution of interest» ${ }^{29}$ que los papeles de la Sibila han sufrido en sus manos (The Last Man: p. 7). A su vez, la narradora subraya cómo se ha visto obligada a «add links, and model the work into a consistent form $»^{30}$ (The Last Man: p. 6), revelando la profunda manipulación que el texto sibilino ha sufrido en sus manos. Al igual que ocurre en el Quijote, la credibilidad de la narración queda puesta seriamente en duda, y se muestra como el producto de la manipulación artística de uno de los agentes narratoriales, en este caso esta primera editora-traductora, que confiesa cómo en ciertas ocasiones ha vestido la narración en «that ideality, which takes the mortal sting from pain» ${ }^{31}$, ya que ha adoptado una actitud identificada, y poco distanciada respecto a su propia lectura (p. 7). El juego con la ficción autorial en The Last Man revela aquello que ya se podía intuir en Frankenstein: Mary Shelley comprendió extremadamente bien la compleja estructura narratorial del Quijote, asimilándola y empleándola como un claro recurso narrativo capaz de establecer la característica vacilación que Tzvetan Todorov (2009: 30) asigna al discurso fantástico, en el que es necesaria una particular «visión ambigua», que permita al lector dudar entre una explicación natural y una explicación sobrenatural de los acontecimientos. La manipulación textual de la editora-traductora, y su declarada actitud exaltada frente a los acontecimientos encontrados en las hojas de la Sibila ofrecen una clara explicación racional para los extraordinarios acontecimientos que el lector puede encontrar en la narración de Lionel Verney, que, amén de la ya mencionada extinción de la especie humana, van desde el establecimiento de un sistema republicano en el Reino Unido, a la presencia de artefactos voladores, una mera quimera en las primeras décadas del siglo XIX. En este sentido, el empleo del recurso de la ficción de fuentes y la ambigüedad claramente cervantina entre fidelidad a estas fuentes y manipulación textual es adaptado al discurso de la literatura fantástica, revelando cómo Shelley toma elementos cervantinos para reformularlos y acomodarlos a sus propios intereses creativos.

28. [Oscuras y caóticas como eran [...] deben su actual forma a mí, su codificadora. Como si le diésemos a otro artista los fragmentos pintados que forman la copia en mosaico de la Transfiguración de San Pedro de Rafael; seguramente las juntaría en una forma, cuyo modo estaría dominado por su particular mente y talento].

29. [Distorsión y disminución del interés].

30. [Añadir nexos, y modelar la obra en una forma consistente].

31. [Aquella idealidad, que se lleva el aguijón mortal del dolor]. 


\subsection{Lodore (1835) y Falkner (1837)}

En las dos últimas novelas de Shelley los paralelos con el Quijote dejan de ser estructurales, y se van a ceñir fundamentalmente a lo temático, más concretamente a lo quijotesco, recurso que por otra parte ya había sido empleado por la autora inglesa en Frankenstein. En Lodore (1835) se puede encontrar toda una galería de personajes cuyo quijotismo sirve a Shelley para hacer comprender mejor sus motivaciones y su ineptitud social (Garrett 2000: 137). Un claro ejemplo de esta ineptitud social asociada al quijotismo puede ser encontrado muy al comienzo de la novela en el personaje de Francis Derham, amigo infantil de Lord Lodore, el personaje central de la obra. Derham es caracterizado por sus locas fantasías e ideas inexplicables: poco dotado para las clases y para los estudios reglados, disfruta enormemente con la lectura de los libros de la más abstrusa filosofía (Lodore: pp. 82-83). En cualquier caso, los personajes más reconociblemente quijotescos de la novela son, sin ningún tipo de duda, Fanny Derham, hija del ya mencionado Francis, y Horatio Saville. Si en su padre Shelley articulaba una mezcla de nobleza y ridiculez característica de ciertos Quijotes ingleses del XVIII, en Fanny Derham los atributos quijotescos son idealizados y se muestran como una transgresión del papel pasivo tradicionalmente asignado a las mujeres, tal y como ha señalado Moskal (2000: 35), siguiendo, pero al mismo tiempo reformulando, la tradición de quijotismo femenino instaurada por Charlotte Lennox $(1730-1804)$ en su Female Quixote $(1752)^{32}$. Fanny, con una clara tendencia a encerrarse en el mundo de su propia mente (Lodore: p. 144), es el resultado de una educación poco convencional diseñada por su padre, que se encargó de instruirla en las lenguas muertas y en otros conocimientos abstrusos, lo que la convierte en una entusiasta de la filosofía y del conocimiento, llenando su cabeza de sueños platónicos (Lodore: p. 144). Como se puede observar, Fanny muestra de nuevo la anteriormente mencionada mezcla entre entusiasmo quijotesco y búsqueda fáustica del conocimiento, pero Shelley se encarga de purgar el quijotismo de este personaje de cualquier aspecto ridículo, convirtiéndola en un símbolo de la independencia intelectual femenina:

She had something Quixotic in her nature; or rather she whould have had,
if a clear head and some experience, even Young as she was, had not stood
in the way of her making any glaring mistakes; so that her enterprises were
never ridiculous; and being usually successful, could not be called ex-
travagant. For herself, she needed but her liberty and her books; - for
others, she had her time, her thoughts, her decided and resolute modes of

32. En este sentido, cabe resaltar que, si bien Arabella emplea la literatura como medio para transgredir los roles de género tradicionalmente asignados a las mujeres, el final de la novela de Lennox castiga y satiriza a Arabella, haciéndola retornar al ámbito de la domesticidad tras el matrimonio. Para un análisis detallado de los Quijotes femeninos del siglo XVIII inglés puede consultarse Gordon (2005 y 2006), Pawl (2000), Pardo (2004 y 2005) y la tesis doctoral de Miriam Borham (2013). 
action, all that their command, whenever she was convinced that they had a just claim upon them (Lodore: p. 323) ${ }^{33}$.

Nos encontramos ante una sublimación e idealización del quijotismo, que es depurado de cualquier aspecto ridículo. En el personaje de Fanny Derham, Shelley se mueve ya plenamente en la interpretación romántica del Quijote.

En el otro gran personaje quijotesco de la novela, Horatio Saville, podemos observar de nuevo una caracterización del quijotismo bastante similar a la encontrada en Frankenstein. A Saville, al igual que a Frankenstein o Walton, le mueve una búsqueda ideal del conocimiento, un intento de revivir lo que la academia había sido en tiempos pasados, que surge de su amor por el conocimiento y el aprendizaje, por su deseo inquebrantable de alcanzar la verdad (Lodore: p. 190). Sin embargo, pese a ciertas similitudes con Frankenstein y Walton, Saville posee la mezcla de cómica singularidad y de nobleza propia de un Parson Adams, algo que lo convierte en un Quijote noble y ridículo al mismo tiempo.

Finalmente, la galería de personajes quijotescos de Lodore se cierra con Ethel, la hija de Lord Lodore. En Ethel ciertos rasgos de quijotismo son de nuevo el producto de la educación ofrecida por su padre y del solitario ambiente de Illinois, en el que crece. Su aislamiento social y la formación solitaria que recibe crean un divorcio entre la realidad y su percepción de esta, especialmente pronunciado en sus nociones del amor, que concibe en términos heroicos e idealizados. Así, el narrador describe cómo «there was something of the Orondates' vein in her ideas; but they were too vague and general to influence her actions» (Lodore: p. 75) ${ }^{34}$. Esta referencia a Orondates, el amante de Casandra en Cassandre (1642) de Gautier de Coste La Calprenède (1609-1663), dirige claramente al lector hacia la crítica del romance heroico francés que Charlotte Lennox realiza en The Female Quixote (1752) a través de su heroína quijotesca, Arabella. Sin embargo, a diferencia de esta, Shelley señala como el quijotismo de Ethel es solamente una cierta coloración romántica en la idea del amor, que no llega a producir un quijotismo activo similar al de la heroína de Lennox. Su matrimonio con Villiers, y su percepción idealista y romantizada de este cuando se ven acuciados por unas necesidades económicas a las que Ethel parece ajena, muestra bien a las claras su divorcio con la realidad. En Ethel, Shelley articula el reverso quijotesco a Fanny Derham. Ambas son influidas por una educación juvenil deficitaria que propicia el quijotismo, pero en el caso de Ethel, al contrario que en el de Fanny, esta

33. [Tenía algo quijotesco en su naturaleza; o más bien lo habría tenido, si una mente despejada y cierta experiencia, pese a su juventud, no se hubiera interpuesto a la hora de cometer errores evidentes, por lo que sus empresas nunca eran ridículas, y siendo habitualmente exitosas, no podrían ser llamadas extravagantes. Para ella, no necesitaba otra cosa que su libertad y sus libros; para los demás, tenía su tiempo, sus pensamientos, sus modos de acción decididos y resueltos, todos ellos a su disposición, siempre que estuviera convencida de que tenían una causa justa sobre ellos].

34. [Había algo del Orondates en sus ideas, pero era demasiado vago y general como para influir en sus acciones]. 
tiene como resultado una excesiva ingenuidad y una clara falta de sentido práctico para el mundo real.

En este sentido, cabe destacar que en la contraposición entre las figuras de Ethel y Fanny encontramos un claro reflejo de las ideas sobre la lectura y la educación de la mujer presentes en la Vindication of the Rights of Woman (1792), de Mary Wollstonecraft. En su obra, Wollstonecraft incluye un capítulo titulado «Algunos ejemplos del desatino que genera la ignorancia de las mujeres; con reflexiones concluyentes sobre el perfeccionamiento moral que se podría esperar que produjera, de forma natural, una revolución en la conducta de las mujeres». El capítulo gira en torno a los ejemplos de necedad, causados por la situación de ignorancia a la que las mujeres han sido forzadas por el patriarcado. La sección segunda de este capítulo se centra específicamente en el «giro romántico de la mente», que Wollstonecraft define como «otro ejemplo de esa debilidad femenina de carácter, con frecuencia producida por una educación limitada», y que hace que determinadas mujeres adquieran «nociones metafísicas respecto a la pasión, que las llevan a descuidar de forma vergonzosa las obligaciones de la vida» (Vindicación de los derechos de la mujer: p. 130). De hecho, Wollstonecraft nos ofrece un retrato bastante preciso de este tipo de mujeres:

Estas son las mujeres que se entretienen con las ensoñaciones de los novelistas estúpidos, que, sabiendo muy poco de la naturaleza humana, construyen relatos manidos y describen escenas rimbombantes, todo ello narrado con una jerga sentimental que tiende de igual forma a corromper el gusto y a apartar el corazón de sus deberes diarios. No menciono el entendimiento, pues, al no haber sido ejercitado, sus energías dormidas permanecen inactivas, como las partículas de fuego ocultas que de forma universal, se supone, permean la materia (Vindicación de los derechos de la mujer: p. 130).

Para Wollstonecraft, la existencia de este tipo de mujeres con «un giro romántico de la mente» se ve motivada por negarse a las mujeres «todos los privilegios políticos y no permitírseles una existencia civil como casadas, salvo en caso de delito» (130), es decir, por la «opresión política y civil» que motiva que «los sentimientos se vuelven acontecimientos» (Vindicación de los derechos de la mujer: p. 130). Wollstonecraft opone la lectura de estas novelas a aquellas lecturas «que excitan el entendimiento y regulan la imaginación», y que permiten a la mente «recibir cierta ampliación» (Vindicación de los derechos de la mujer: p. 131). La escritora inglesa afirma cómo su objetivo es inducir a las mujeres «a leer algo superior» (Vindicación de los derechos de la mujer: p. 133), y de hecho menciona el remedio de la sátira, quizás la mejor medicina para curar el gusto por estas producciones literarias:

Considero que el mejor método que puede adoptarse para corregir la afición por las novelas es ridiculizarlas, no de forma indiscriminada, porque entonces tendría poco efecto; pero si una persona juiciosa, con algún sentido 
del humor, leyera algunas a una joven y subrayase, mediante la entonación y comparaciones apropiadas con patéticos hechos y personajes heroicos de la historia, de qué modo tan insensato y ridículo caricaturizan la naturaleza humana, las opiniones justas podrían sustituir a los hechos románticos (Vindicación de los derechos de la mujer: p. 134).

La revolución respecto a la mujer y sus derechos pasa, necesariamente, por su involucración en la sociedad civil, y por una reforma de sus lecturas, sustituyendo la literatura sentimental, volcada en la interioridad y en unos sentimientos artificiosos, por una literatura que inspire un verdadero espíritu cívico, y que permita a las mujeres imbricarse en la sociedad. En este sentido, no resulta sorprendente ver a Mary Shelley reproducir, casi de manera literal, las ideas de su madre en los personajes de Ethel y Fanny Derham. Si en Ethel Lodore nos encontramos con una educación deficitaria, solitaria, y basada en las lecturas sentimentales anteriormente mencionadas, vinculando de esta manera su figura a la del quijotismo femenino más tradicional y de claro corte satírico, en Fanny se puede hallar una clara reinterpretación por parte de Shelley de la figura del Female Quixote. Como se ha mencionado anteriormente, Shelley purga a Fanny de cualquier aspecto satírico o cómico, y se afana en subrayar lo extraordinario de su educación y su afición por la Filosofía y por las lenguas muertas, precisamente el tipo de educación vedado a las mujeres que Wollstonecraft plantea como un modelo adecuado para estas en su Vindication of the Rights of Woman. De este modo, Shelley no «abraza, y parcialmente rechaza» la tradición del Female Quixote claramente asociada con la obra de su madre tal y como apunta Moskal (2000: 18), sino que más bien ejemplifica imaginativamente las ideas de Wollstonecraft respecto a la educación de las mujeres y su rol como lectoras ${ }^{35}$. En Lodore se pueden encontrar dos claros modelos de ejemplaridad positiva y negativa de mujeres lectoras, y en el retrato de Fanny Derham, románticamente idealizada por Shelley, el lector se ve confrontado con una clara ejemplificación la revolución feminista que Wollstonecraft predicó en sus escritos. El quijotismo femenino transgrede en la obra de Shelley el papel censor y reafirmador del status quo que la tradición del Female Quixote de Lennox instauró en el siglo XVIII, y convierte a Fanny en un modelo de independencia intelectual femenina, de «sentido común, es decir, de una forma precisa de ver los hechos comunes, desde una perspectiva distanciada» (Vindicación de los derechos de la mujer: p. 133$)^{36}$.

35. En este sentido, es de recibo recordar la anteriormente mencionada misiva de Mary Shelley a John Howard Payne en 1825, en la que la autora de Frankenstein se define a sí misma como «female Quixote that I am» (Letters, I: 499-500).

36. Darcy Donahue (2009: 184) también ha destacado el uso del quijotismo que Shelley emplea en Lodore para caracterizar a las figuras de Ethel y Fanny, subrayando cómo «both young women are quixotic. Ethel in her idealized visión of herself as Dulcinea and her husband as Don Quixote, and Fanny in her rejection of social convention». 
Gracias a esta variedad de peculiares figuras, Shelley reúne en su novela diversas manifestaciones del quijotismo, a través de las cuales retrata el negativo aislamiento de sus personajes, pero también las cualidades más positivas del fenómeno, encarnadas en una Fanny Derham siempre dispuesta a interceder en favor de los menesterosos gracias a su espíritu quijotesco pasado por el filtro de la experiencia.

En Falkner (1837), la última novela publicada por la autora de Frankenstein, nos encontramos nuevamente con una cierta actitud quijotesca en los dos personajes centrales de la novela, Rupert Falkner y Gerald Neville, enfrentados por el asesinato accidental de la madre de Neville por parte de Falkner ${ }^{37}$. La novela, que gira en torno a la reconciliación de estos dos personajes y su relación con Elizabeth Ruby, recurre de nuevo al quijotismo a la hora de caracterizar a ambos. En el caso de Neville, la influencia de Elizabeth servirá para curarle de su «devoción quijotesca» y del «entusiasmo natural a su disposición» que generalmente se materializa en «vanas empresas» (Falkner 265). De nuevo nos encontramos con la asociación entre entusiasmo y quijotismo, tan recurrente en Shelley. Si en este caso el quijotismo es un problema que debe ser solucionado, en el de su antagonista, Rupert Falkner, se convierte en uno de sus pocos atributos positivos, tal como se enuncia de forma explícita, pues se manifiesta como la capacidad ideal de ayudar a los oprimidos y menesterosos: «Falkner had, with all his suffering and his faults, much of the Don Quixote about him, and never heard a story of oppression without forming a scheme to relieve the victim» $(86)^{38}$. Al igual que en Lodore, el quijotismo se convierte en una de las claves en la caracterización de los personajes de esta última novela de Shelley, trazando así un círculo de clara influencia cervantina en la carrera literaria de Mary Shelley, un círculo que se inicia con su primera novela, y que termina con su última producción novelística, revelando cómo Cervantes y su Ingenioso Hidalgo suponen una influencia decisiva en la carrera literaria de la autora del Moderno Prometeo.

\section{MARY SHELLEY CERVANTISTA: LIFE OF CERVANTES (1837)}

Este repaso a la influencia de Miguel de Cervantes en la carrera literaria de Mary Shelley no puede cerrarse sin hacer referencia a una de sus últimas obras, su Life of Cervantes, aparecida en 1837 en el tercer volumen de las Literary Lives of the Most Eminent Literary and Scientific Men of Italy, Spain,

37. Cabe destacar que Shelley se encontraba inmersa en el trabajo de redacción de esta novela en el mismo año en el que aparece su Life of Cervantes por lo que, como destaca Donahue (2009: 185): «The Cervantine protagonist would have been a ready literary model upon which to draw for Falkner's redeeming qualities».

38. [Falkner tenía, con todo su sufrimiento y sus defectos, mucho en él de don Quijote, y nunca escuchó una historia de opresión sin formar un plan para salvar a la víctima]. 
and Portugal (1835-1837) publicada para la Cabinet Cyclopaedia del irlandés Dionysius Lardner ${ }^{39}$, obra que sitúa a Shelley como una de las precursoras del cervantismo británico, ya que su biografía del autor alcalaíno supone una de las primeras aproximaciones críticas a la obra de Cervantes desde las contribuciones del Reverendo John Bowle (1725-1788) y Samuel Taylor Coleridge $(1772-1834)^{40}$. En su biografía, Shelley va a presentar a un Cervantes romantizado, heroico y acorde a la estética del genio, pero también va a utilizar sus páginas cervantinas como espejo vital e ideológico, no en vano, como destaca Antonio Sánchez Jiménez (2016: 24) en su magnífica y reciente edición de esta biografía y de la de Lope, también presente en las Literary Lives, «hay mucho de la autora en estas obras, de su talento, de sus emociones, de su ideología», aspecto en el que también coincide Lisa Vargo (2002: xvi), que considera el trabajo de Shelley como «a highly politicised work [...] also a deeply personal one».

Desde el comienzo de la biografía, la más larga de las Spanish Lives y que asume la estructura característica de la biografía johnsoniana, es decir, una presentación de la vida y la personalidad del autor seguida de un resumen de sus obras, trufado con extractos de estas (Vargo 2002: xxiv), Shelley ofrece una imagen de Cervantes acorde con la estética del genio tan propia del movimiento romántico ${ }^{41}$. Como destaca Sánchez Jiménez (2016: 24-25), Shelley

39. Es de destacar que entre 1830 y 1832 Lardner había encargado biografías de Cervantes, Lope de Vega, Camoens y Calderón de la Barca, aunque parece que estas fueron descartadas en favor de las biografías escritas por Shelley entre 1835 y 1839 . Entre los posibles autores de estas biografías que jamás verían la luz, y particularmente de la biografía de Cervantes, Lisa Vargo (2002: xxvi) se inclina por Thomas Roscoe, que ya había publicado una biografía de Cervantes en 1833, en la que esta investigadora encuentra pocas similitudes con el trabajo de Shelley. Los otros dos posibles candidatos serían Samuel Astley Dunham, que ya había colaborado con Lardner y cuyas contribuciones nunca fueron rechazadas (Vargo 2002: xxxvi) y Robert Southey, en ese momento Poeta Laureado, rango que incita a considerar un posible rechazo a una de sus contribuciones como poco plausible (Vargo 2002: xxxvi).

40. Me refiero a la edición crítica y anotada en castellano del Rev. Bowle, Historia del valeroso caballero Don Quijote de la Mancha, to be illustrated by annotations and extracts from the Historians, Poets, and romances of Spain and Italy, and other Writers Ancient and Modern; with a Glossary and indexes, in which are occasionally interspersed Some Reflections on the Learning and Genius of the Author, with a Map of Spain, adapted to the History, and to Every Translation of it (1781); y a los juicios que Coleridge dedicó al Quijote en una de sus lecciones magistrales, aparentemente del 12 de julio de 1827, compilados en su Table Talk (1835) (Vargo 2002: 159). A esta lista cabría añadir la traducción de Jarvis de 1742, que incluía la traducción de la biografía de Mayans y Siscar publicada para la edición comisionada por Lord Carteret en 1738. A su vez, cabe subrayar que en un contexto temporal más cercano al trabajo de Shelley, el escocés John Gibson Lockhart ya había publicado una pequeña biografía cervantina en su introducción a la reedición de la traducción de Peter Motteux publicada en 1822, "The Life of Cervantes», mientras que Thomas Roscoe, que traduciría la biografía de Cervantes de Fernández de Navarrete en 1839, ya había publicado una pequeña biografía cervantina en la reedición de la traducción del Tobias Smollett de 1832.

41. No fueron pocas las dificultades con las que Mary Shelley se encontró a la hora de redactar su biografía. En una carta de 1835 a María Gisborn, la autora inglesa se queja de la dificultad en obtener fuentes relacionadas con la literatura española (Letters, II: p. 257). En ese mismo año buscó la ayuda de su amigo John Bowring, que como se ha mencionado anteriormente era un auténtico erudito en cuestiones hispanas (Letters, II: pp. 254-255), y que parece que proporcionó a la autora la biografía cervantina de Vicente de los Ríos para la Real Academia de 1780. Según Lisa Vargo (2002: 
se afana en ofrecer «un personaje a la altura de su obra», situando al autor español por encima de Shakespeare, y convirtiendo al Quijote no en una obra española, sino de significación universal. Estas son las palabras con las que Shelley inicia su biografía cervantina:

It is most certain, that all those capable of feeling a generous interest in the fate of genius will turn with eager curiosity to the page inscribed with the name of Cervantes: not even Shakespeare has so universal a reputation. While the sublime character of Don Quixote warms the heart of the enthusiast, the truth of the sad picture which his fortunes presents tickles the fancy of the man of the world. Children revel in the comedy, old men admire the shrewdness, of Sancho Panza. That this work is written in prose increases its popularity. Imperfect as all translations must be, none fail so entirely as those which attempt to transfuse the ethereal and delicate spirit of verse into another language. But though to read "Don Quixote" in its native Spanish infinitely increases the pleasure it affords, yet so does its mere meaning speak to all mankind, that even a translation satisfies those who are thus forced to content themselves (Lives 119) ${ }^{42}$.

Shelley, además, equipara a Cervantes con su creación, y al destacar cómo Cervantes tuvo una vida llena de adversidades, la autora inglesa apunta cómo «we desire to learn with what spirit he endured adversity — whether, like his heroic creation, he consoled himself at the worst by the sense of conscious

xxii), las principales fuentes bibliográficas que Shelley sigue en sus biografías son el Parnaso Español (1768-1778) de José López de Sedano; la traducción de la Geschichte der neuern Poesie und Bererdsamkeit (1801-1819) de Friedrich Bouterwerk llevada a cabo por Thomasina Ross en 1823; la obra De la littérature du midi de l'Europe (1813) del suizo Sismondi y finalmente algunos artículos escritos por Bowring para el Quarterly y el Retrospective Review. En lo que se refiere a las fuentes para su biografía de Cervantes, Shelley sigue las biografías de Juan Antonio Pellicer (1797), Vicente de los Ríos (1780) y Viardot (1836). En cualquier caso, Vargo (2002: xxii) destaca que Shelley no sigue a sus fuentes (fundamentalmente a Viardot) ciegamente, demostrando cómo «there is always a sense of an engaged and intelligent mind at work weighing what should be included, what seems accurate, even if she cannot be privy to information gleaned by subsequent scholarship». De hecho, en varias ocasiones Shelley presenta sus propias traducciones de la propia poesía de Cervantes (destacando su traducción del poema dedicado al túmulo del Rey en Sevilla) o de pasajes de Los Baños de Argel, traslaciones al inglés de un mérito incuestionable y que demuestran cómo la autora inglesa no se limitó a seguir ciegamente otras fuentes.

42. «Es seguro que todos aquellos capaces de sentir un interés generoso por el destino de un genio se lanzarán con viva curiosidad a las páginas que lleven el nombre de Cervantes, ni siquiera Shakespeare goza de una reputación tan universal. Mientras el sublime carácter de Don Quijote anima el corazón del entusiasta, la verdad de la triste imagen que componen sus desventuras despierta la imaginación del hombre de mundo. Los niños disfrutan con la comedia de Sancho Panza, los viejos admiran su astucia. Además, el hecho de que este libro esté escrito en prosa aumenta su popularidad. Aunque toda traducción es por naturaleza imperfecta, ninguna fracasa con tanto estrépito como la que intenta trasladar el etéreo y delicado espíritu del verso a otra lengua. Pero aunque leer Don Quijote en español, su lengua original, aumenta enormemente el placer que provoca su lectura, ya el sentido del libro es bastante para conectar de tal modo con cualquier ser humano que incluso una traducción satisface a los que se tienen que contentar con ella» (Vida de Cervantes: p. 41). 
worth and virtuous intention» ${ }^{43}$ (Lives: p. 119), llegando incluso a preguntarse si Cervantes, como su héroe, conservó «a serene and undaunted spirit in the midst of blows and derision» (Lives: p. 119) ${ }^{44}$. La figura de don Quijote, equiparable a la del propio Cervantes, es entendida por Shelley como un personaje «as courageous, noble, princely, and virtuous as the greatest of the men whom he imitates» ${ }^{45}$ (Lives: p. 163), como alguien que «meeting all, and bearing all with courage and equanimity, he really becomes the hero he desired to be» (Lives: p. 163) (6) $^{4}$ En consecuencia, la figura de Cervantes ha de ser puesta a la altura de la visión romantizada que Shelley ofrece de su protagonista, y como destaca Sánchez Jiménez (2016: 25), la autora inglesa «explora extensamente los hechos más heroicos - y ciertamente, también más dramáticos- de la vida de Cervantes (Lepanto y el cautiverio de Argel)», soslayando «otros menos luminosos (sus encarcelamientos), en los que, además, se esfuerza por exonerar al escritor de cualquier asomo de culpa». Así, por ejemplo, tras la descripción del episodio de Lepanto, y la narración del cautiverio del autor en Argel, Shelley nos pinta a un Cervantes caracterizado por el valor y el heroísmo (Lives: p. 133), destacando su conducta como la de un hombre de sagacidad, resolución, y honor (Lives: p. 127).

El retrato prácticamente hagiográfico que Shelley ofrece de Cervantes, que es contrastado constantemente con sus miserias vitales, propiciadas por la mala fortuna y por una España despótica y atrasada, permite a Shelley, como ha destacado Sánchez Jiménez (2016) con el acierto que le caracteriza, tejer una serie de identificaciones entre la vida de Cervantes y su propia vida, que fue rica en infortunios, entre ellos la muerte prematura de dos hijos y de Percy Shelley, así como toda una galería de penurias económicas derivadas de la muerte del poeta inglés. En palabras del catedrático de la Universidad de Neuchâtel, «la propia Mary se identifica claramente con Cervantes y resulta difícil no ver en su interés por los problemas económicos del alcalaíno un reflejo de los que Mary y su familia sufrieron durante parte de su vida, paralelismo que también explicaría otra imagen que le gustaba presentar a la autora: la de Cervantes recurriendo a la literatura para refugiarse de los golpes de un hado hostil» (Sánchez Jiménez 2016: 26) ${ }^{47}$. En efecto, el pasaje en el que la escritora inglesa se refiere a los pocos testimonios personales que Cervantes ofrece de su cautiverio resulta una perfecta imagen de esta asocia-

43. «Deseamos saber con qué animo soportó la adversidad, saber si, como su heroico personaje, se consoló en sus peores momentos con la conciencia de su valor y virtuosa intención» (Vida de Cervantes 41).

44. «El espíritu sereno e imbatido en medio de los golpes y el ridículo» (Vida de Cervantes: pp. 41-42).

45. «Tan valeroso, noble, principesco y virtuoso como los mejores caballeros a los que imita» (Vida de Cervantes: p. 117).

46. «Enfrentándose a todo, y soportándolo todo con valor y ecuanimidad, se convierte realmente en el héroe que quería ser» (Vida de Cervantes: p. 118).

47. Lisa Vargo (2002: xxv) muestra una opinión distinta, ya que para la investigadora norteamericana, la biografía cervantina de Shelley refleja las adversidades de la vida de su propio padre. 


\section{ción entre la vida de Cervantes y la propia, de esta proyección de la vida propia en la vida ajena:}

As Cervantes often alludes to himself, it is strange that he did not write an account of his years of captivity; but the truth is, that though we may be led to mention ourselves, it is ever a tedious task to write at length on the subject: recollections come by crowds; hopes baffled, our dearest memories discovered to have a taint, our lives wasted and fallen into contempt even in our own eyes, so that we readily turn from dispiriting realities to such creatures of the imagination as we can fashion according to our own liking (Lives: pp. 128-129) ${ }^{48}$.

La literatura, por lo tanto, se convierte en un poderoso medio para exorcizar las penurias vitales, y en este sentido, la vida de Cervantes supone un perfecto ejemplo de un proceso que Mary Shelley experimentó quizás con demasiada frecuencia ${ }^{49}$.

48. «Puesto que Cervantes aludió a sí mismo con frecuencia, resulta extraño que no escribiera una relación de sus años de cautiverio, pero lo cierto es que, aunque a veces nos veamos obligados a hablar de nosotros mismos, siempre es tedioso tratar este tema en detalle: los recuerdos llegan en muchedumbre, las esperanzas, frustradas, las reminiscencias más queridas nos parecen manchadas, nuestras vidas, malgastadas y despreciables ante nuestros propios ojos, así que muy rápidamente nos apartamos de estas desalentadoras verdades para refugiarnos en criaturas de nuestra imaginación, que podamos forzar a nuestro gusto» (Vida de Cervantes: p. 57).

49. Esta idea es recurrente en la Life of Cervantes de Shelley. Al referirse al episodio del encarcelamiento en Argamasilla de Alba, Shelley ve en la gestación del Quijote una suerte de bálsamo frente a la adversidad: «It is imposible here not to remember the beautiful image of lord Bacon, that calamity acts on the highminded as the crushing of perfumes, pressing the innate virtue out of each: for in this prison Cervantes wrote "Don Quixote." When we consider the ill-fortune that pursued him - his military career, which left him maimed and unrewarded — his captivity in Algiers, where he exerted a spirit of resistance sublime in its fearlessness and its risks, and whence he returned a beggar - his life spent as a sort of clerk where he gained his scanty daily bread, at the mercy of the arbitrary and litigious ministers of Spanish justice — and that he endured all the distresses incident to straitened means and friendlessness; when we consider that the end of all was to throw him into a squalid prison in an obscure village, where he must have felt all hopes, not only of advancement, but of attaining the means of existence, fail him — where in a dreary cavern-like chamber he passed long days and sleepless nights, weary and worn out: — when we think that he was now fifty-six years of age, a period when the fire of life burns dim - and then, when we compare all these sad depressing circumstances with the very outset of "Don Quixote," we feel that there must have been something divine in the spirit of this man, which could place a soul within the ribs of death, and vivify darkness and suffering with so animated a creation» (Lives 144). [Es imposible no traer aquí a colación una bella imagen de Lord Bacon: la desgracia actúa sobre las mentes elevadas como la presión en el caso de los perfumes, extrayendo la virtud innata de cada uno, pues en esta prisión, Cervantes escribió Don Quijote. Cuando consideramos las desventuras que le acosaban — su carrera militar, que le dejó tullido y sin recompensa, su cautiverio en Argel, donde mostró una fuerza de voluntad sublime en valor y riesgos y de donde regresa hecho un mendigo, su vida consumida trabajando como una suerte de funcionario que ganaba su escaso pan sometido a los arbitrarios y litigiosos ministros de la justicia española, y comprobamos que resistió todas las desgracias anejas a la escasez de medios y la falta de amigos, cuando consideramos que al final de todas estas tribulaciones fue arrojado a una lóbrega prisión en un pueblo perdido, en la que debió de perder toda esperanza no solo de ascender socialmente, sino también de ganarse la vida, donde en una horrible mazmorra cavernosa pasó largos días y noches insomnes, consumido y cansado, cuando pensamos que tenía ya cincuenta y seis años, una etapa en la que el fuego de la vida se comienza a debilitar, y finalmente, cuando comparamos estas 
Si Cervantes y sus penurias sirvieron como espejo vital para la propia Mary Shelley, la confrontación entre el genio y la sociedad es empleada por la autora inglesa para convertir a Cervantes en un «paladín de las ideas progresistas liberales» (Sánchez Jiménez 2016: 25). Shelley confronta en numerosas ocasiones el genio de Cervantes con la mezquindad de la sociedad española, a la que otorga trazos de la Leyenda Negra, como destaca Sánchez Jiménez (2016: 28-29). Así, al relatar las dificultades experimentadas por Cervantes a su vuelta del cautiverio de Argel, Shelley dedica estas vehementes palabras a la situación del autor español:

It inspires infinite contempt for the arbitrary distinctions of society when we find this prince and leader among his fellows was, when restored to his native country, depressed by poverty and obscured by want; and when we find no spirit of repining displayed during his after life, though he had dignity of soul to assert his worth, we are impelled to give Cervantes as high a place for moral excellence as his genius secured him for the world of intellect (Lives: p. 135) ${ }^{50}$.

Esta confrontación entre la impoluta moralidad de Cervantes y la degradada sociedad española encuentra nuevos reflejos en los episodios de encarcelamiento de Cervantes, que reflejan, para Shelley, la arbitrariedad de la justicia española (Lives: p. 144). De hecho, al hablar de las sátiras y críticas que suscitó la publicación de la primera parte del Quijote, Shelley llega a sugerir que la España del siglo XVII no fue un territorio particularmente fértil para las musas:

A cloud of satires, epigrams, and criticisms were leveled against his work. Old rough doctor Johnson would have reveled in such testimony of his popularity, and Cervantes was at least secure in having the laugh on his side. Los Rios, however, observes that if the many satires, attacks and persecutions, which the author and his book suffered had not been submerged in oblivion, or drowned in the quantity of eulogies and defences heaped on him by men of talent, who continued to substract such disagreeable productions from the eyes of posterity, it would now appear, that "Don Quixote" had been written in the midst of a nation enemy to the muses (Lives: p. 148) ${ }^{51}$.

tristes y deprimentes circunstancias con el comienzo de Don Quijote, sentimos que debe de haber habido algo divino en el espíritu de este hombre, algo que podría confrontar un alma con el espinazo de la muerte y vivificar la oscuridad y el sufrimiento con semejante creación (Vida de Cervantes: p. 84)].

50. «Sentimos un infinito desprecio hacia las arbitrarias distinciones de la sociedad cuando descubrimos que, cuando se le devolvió a su país natal, este príncipe y guía de sus compañeros se vio deprimido por la pobreza y acosado por la necesidad, y cuando no encontramos ninguna queja tras su muerte nos sentimos impelidos a otorgarle a Cervantes un lugar tan alto por su excelencia moral como el que su genio le ha asegurado en el mundo del intelecto» (Vida de Cervantes: p. 68).

51. «Una nube de sátiras, epigramas y críticas se abatió sobre el libro. Al viejo y endurecido doctor Johnson le habría encantado ver semejante testimonio de su popularidad y Cervantes al menos estaba seguro de que sería él el que más se reiría. Sin embargo, de los Ríos observa que si no llega 
La España del XVII, que en parte criticó y satirizó el Quijote, no estaba preparada, a juicio de Shelley, para Cervantes y su novela, obra que entiende como una obra «perfect in all its parts» (Lives: p. 164) ${ }^{52}$. Sin embargo, la apreciación sobre la capacidad crítica de España respecto a la obra de Cervantes cambia radicalmente al referirse Shelley a la Numancia cervantina y, más concretamente a su representación durante el sitio de Zaragoza. Shelley, que muestra su clara preferencia por la Numancia en lo que se refiere a la producción teatral cervantina, definiéndola como «a monument worthy of Cervantes's genius, and proves the height to which he could soar, and brings him yet in closer resemblance to Shakespeare, showing that he could depict the grand and terrible, the pathetic and the deeply tragic, with the same master hand ${ }^{53}$ (Lives: p. 161), subraya cómo «the Spaniards found in the example of their forefathers, and in the spirit and grand genius of their greatest man, fresh inducements to resist» (161), definiendo este hecho como «a triumph of Cervantes, worthy of him, and shows how truly and how well he could speak to the hearts of his countrymen» $(161)^{54}$. Es digno de destacar cómo una de las pocas referencias claramente positivas que España encuentra en la Life of Cervantes se halla precisamente en el contexto de las Guerras Napoleónicas, vinculando al pueblo español, y por ende, a Cervantes, con el espíritu de la Constitución de Cádiz, acontecimiento que, como se ha podido apreciar anteriormente, Shelley siguió con particular interés. Cervantes es reclamado de esta sutil manera para la agenda política jacobina de la escritora inglesa, evidenciando la apropiación estética, vital, y finalmente, política,

a ser porque las numerosas sátiras, ataques y persecuciones que sufrieron el libro y su autor acabaron siendo engullidas por el olvido $\mathrm{u}$ ahogadas por la cantidad de elogios y defensas que amontonaron sobre él los hombres de talento, ahora nos parecería que Don Quijote había sido escrita en una nación enemiga de las musas» (Vida de Cervantes: p. 90).

52. En lo que se refiere a la opinión de Shelley sobre el Quijote, muy condensada dentro del resto de opiniones en torno a la obra de Cervantes, la autora inglesa aprecia una clara diferencia entre las dos partes de la novela cervantina. Para Shelley, la primera parte es admirable en su concepción, ya que «the idea of the crazed old gentleman who nourished himself in the perusal of romances till he wanted to be the hero of one is true to the very end of nature» (Lives: p. 164) [la imagen de un viejo hidalgo que se alimenta manejando sus novelas hasta que quiere convertirse en protagonista de una de ellas es fiel a la más pura verdad de la naturaleza (Vida de Cervantes: p. 117)], mientras que la segunda parte, en la que encuentra «less extravagance, less of actual insanity on the part of the hero» [menos extravagancia, menos locuras del protagonista (Vida de Cervantes: p. 118)] le parece «less entertaining to the general reader, less original, less brilliant; but it is more philosophic, more full of the author himself: it shows the deep sagacity of Cervantes and his perfect knowledge of the human heart» (Lives: p. 164) [menos entretenida para el público general, menos original, menos brillante; pero es más filosófica, más llena del espíritu del autor: muestra la profunda sagacidad de Cervantes y su perfecto conocimiento del corazón humano (Vida de Cervantes: p. 118)]. Al igual que lectores posteriores como Nabokov, Shelley lamenta la extrema crueldad de los duques en los episodios del palacio ducal (Lives: p. 164).

53. «Un monumento digno del genio de Cervantes [que] demuestra las alturas a las que podía elevarse, asemejándole aún más a Shakespeare, mostrando que sabía pintar lo grandioso, lo terrible, y lo profundamente trágico con la misma mano maestra» (Vida de Cervantes: p. 112-113).

54. «Los españoles hallaron en el ejemplo de sus antepasados y en el espíritu y genio del más grande de sus compatriotas ánimos para resistir [...] un triunfo de Cervantes, digno de él, y muestra hasta qué punto podía conectar con los corazones de los españoles» (Vida de Cervantes: p. 112-113). 
que Shelley hace de la figura de Cervantes y de su obra no sólo en su biografía cervantina, sino a lo largo de toda su carrera como escritora.

\section{FUENTES}

Anónimo (1782). The Philosophical Quixote, or the Memoirs of David Wilkins, in a series of Letters. Londres: J. Johnson.

Byron, George Gordon, Lord (2008). The Major Works. Oxford: Oxford University Press. Hunt, Leigh (1846). The Poetical Works. London: Edward Maxon, 1846.

Hunt, Leigh (1850). The Autobiography of Leigh Hunt. With Remniscences of Friends and Contemporaries (3 vols.). London: Smith Elder \& Co.

Scott, Walter (2008). Waverley, or 'Tis Sixty Years Since. Oxford: Oxford University Press, 2008.

Shelley, Mary (1837). Falkner. A Novel. New York: Saunders and Otley, 1837.

Shelley, Mary (1980). The Letters of Mary Wolstonecraft Shelley, Betty T. Bennett (ed.). Baltimore: The John Hopkins University Press, 2 vols.

Shelley, Mary (1987). The Journals of Mary Shelley. 1814-1844, Paula R. Feldman y Diana Scott-Kilvert (ed.). Oxford: Clarendon Press, 2 vols.

Shelley, Mary (1995). Selected Letters of Mary Wollstonecraft Shelley, Betty T. Bennett (ed.). Baltimore: The John Hopkins University Press.

Shelley, Mary (1997). Lodore. Peterborough (Ontario): Broadview Literary Texts.

Shelley, Mary (2002). Mary Shelley's Literary Lives and Other Writings. Vol. 2. Spanish and Portuguese Lives, Lisa Vargo (ed.). London: Pickering and Chatto.

Shelley, Mary (2008). The Last Man. Oxford: Oxford University Press.

Shelley, Mary (2008) [1818]. Frankenstein, or the Modern Prometheus, Marylin Butler (ed.). Oxford: Oxford University Press.

Shelley, Mary (2010). History of a Six Weeks' Tour. Memphis (Tennessee): General Books.

Shelley, Mary (2016). Cervantes y Lope. Vidas Paralelas, Antonio Sánchez Jiménez (ed.). Barcelona: Calambur, 2016.

Shelley, Percy (2009). The Major Works. Oxford: Oxford University Press.

Wollstonecraft, Mary (2002). Vindicación de los derechos de la mujer, Marta Lois González (trad.). Madrid: Taurus.

\section{BIBLIOGRAFÍA CITADA}

Borham, Miriam (2013). Quixotic Readers and Quixotic Writers: Cervantes's Daughters in British Narrative Fiction from Lennon to Austen. Tesis doctoral, Universidad de Salamanca.

De Armas, Frederick A. (2011). Don Quixote among the Sarracens: A Clash of Civilizations and Literary Genres. Toronto: University of Toronto Press.

Donahue, Darcy (2009). «Cervantes as Romantic Hero and Author: Mary Shelley's Life of Cervantes», en J. A. G. Ardila (ed.), The Cervantean Heritage: Reception and Influence of Cervantes in Britain. London: Legenda, pp. 181-190.

El Saffar, Ruth (1975). Distance and Control in Don Quixote: A Study in Narrative Technique. Chapel Hill: University of North Carolina Press. 
Garrett, Erin Webster (2000). «Recycling Zoraida: The Muslim Heroine in Mary Shelley's Frankenstein», Cervantes: Bulletin of the Cervantes Society of America. 20, 1, pp. 133156.

Gordon, Scott Paul (2005). «Female Quixotism: Charlotte Lennox and Tabitha Tenney», en Darío Fernández Morera y Michael Hanke (ed.), Cervantes in the English Speaking World: New Essays. Barcelona: Reichenberger, pp. 127-147.

Gordon, Scott Paul (2006). The Practice of Quixotism. Postmodern Theory and Eighteenth Century Women's Writing. New York: Palgrave MacMillan.

Moro, Alfredo (2013). «"Everything must have a beginning, to speak in Sanchean Phrase”: Frankenstein (1818) de Mary Shelley como novela cervantina», en Carlos Mata Induráin (ed.), Recreaciones quijotescas y cervantinas en la narrativa. Pamplona: EUNSA, pp. 185-195.

Moro, Alfredo (2015a). «Cervantes y lo fantástico: una reexaminación a través de la obra de Mary Shelley», en Marco Kunz y José Miguel Sardiñas (ed.), Paisajes góticos. De lo fantástico y sus alrededores. Binges: Orbius Tertius, pp. 11-23.

Moro, Alfredo (2015b). «Calderón de la Barca en la obra de Mary Shelley», Cuadernos de Ilustración y Romanticismo. 21, pp. 193-203.

Moro, Alfredo (2016). Transformaciones de la novela cervantina en la narrativa inglesa $y$ alemana del siglo XVIII. Alcalá de Henares: Ediciones Universidad Alcalá de Henares.

Moskal, Jeanne (2000). «To speak in Sanchean Phrase: Cervantes and the Politics of Mary Shelley's History of a Six Weeks' Tour», en B. T. Bennett y S. Curran (ed.), Mary Shelley in Her Times. Baltimore: John Hopkins University Press, pp. 18-37.

Palacio, Jean de (1969). Mary Shelley dans son oeuvre: Contributions aux études shelleyenes. Paris: Klincksieck.

Pardo, Pedro Javier (2004). «El Quijote femenino como variante del mito Quijotesco», en Actas del V Congreso Internacional de la Asociación de Cervantistas. [Madrid]: Asociación de Cervantistas, pp. 1627-1644.

Pardo, Pedro Javier (2005). «La heroína quijotesca en la novela inglesa del siglo XIX: Jane Austen, George Eliot y otros novelistas», en Diego Martínez Torrón (ed.), Cervantes y el ámbito anglo-sajón. Madrid: Sial, pp. 356-375.

Paulson, Ronald (1998). Don Quixote in England: The Aesthetics of Laughter. Baltimore: The Johns Hopkins University Press.

Pawl, Amy (2000). «Femenine Transformations of the Quixote in Eighteenth-Century England: Lennox's Female Quixote and Her Sisters», en Barbara A. Simerka y Christopher Weimer (ed.), Echoes and Inscriptions: Comparative Approaches to Early Modern Spanish Literatures. Lewisburg, PA: Bucknell University Press, pp. 142-159.

Pollin, Burton R. (1964). «William Godwin's Fragment of a Romance», Comparative Literature. XVI, pp. 43-44.

Porter, Laurence (2005). Women's Vision in Literature. The Emphatic Community. Westport: Praeger.

Sánchez Jiménez, Antonio (2016). «Introducción», en Cervantes y Lope. Vidas Paralelas. Barcelona: Calambur, pp. 13-35.

Todorov, Tzvetan (2009). Introducción a la literatura fantástica. México D. F.: Ediciones Coyoacán.

Vargo, Lisa (ed.) (2002). Mary Shelley's Literary Lives and Other Writings. Vol. 2. Spanish and Portuguese Lives. London: Pickering and Chatto. 